\title{
DUAS ÉTICAS DA ESQUERDA HEGELIANA: DA COMPAIXÃO EM SCHOPENHAUER E DA SENSIBILIDADE EM FEUERBACH
}

Two ethics of the hegelian left: The compassion in Schopenhauer and the sensitivity in Feuerbach

\section{Luédlley Raynner de Souza Lira ${ }^{1}$ Jheovanne Gamaliel Silva de Abreu $^{2}$}

RESUMO: Arthur Schopenhauer (1788-1860) e Ludwig Feuerbach (1804-1872) foram dois filósofos da então conhecida esquerda hegeliana, por produzirem um pensamento profundamente crítico à Hegel. O objetivo deste trabalho é o de desenvolver semelhanças e divergências entre a ética destes dois pensadores que compartilhavam aversão ao hegelianismo. A metodologia utilizada no desenvolvimento deste trabalho foi a dedutiva com técnica metodológica a análise bibliográfica utilizando as obras de Schopenhauer: O mundo como vontade e como representação, e a de Feuerbach: A essência do cristianismo, bem como alguns de seus comentadores. A ética em Schopenhauer é a da compaixão, isto é, o sentimento de colocar-se no lugar do outro. Por mais que o pensamento schopenhaueriano ser ateísta, a ética da compaixão trata-se de uma concepção cristã que para o filósofo de Dantzig, proporciona uma amenização ao sofrimento causado pelo grilhão da Vontade. Já em Feuerbach, não há um escrito estritamente ligado a ética, o que torna muitas das reflexões e conclusões subjetivas e necessárias de uma ampla interpretação do filósofo. A ética de Feuerbach está intimamente ligada com sua visão materialista de mundo. O homem é um ser dotado de afeto, sentimentos, e tudo que o constitui como ser material, negando qualquer possibilidade de um campo espiritual ou metafísico. Assim, a ética da sensibilidade é o reconhecimento de que o homem é um ser individual e concreto, onde o marco de seu agir deve ser o amor, possibilitando uma vivência material entre todos.

PALAVRAS-CHAVE: Compaixão, Sensibilidade, Vontade, Amor, Contemporaneidade.

\begin{abstract}
Arthur Schopenhauer (1788-1860) and Ludwig Feuerbach (1804-1872) were two philosophers from the then known as left hegelian, for producing a deeply critical thinking of Hegel. The objective of this work is to develop similarities and differences between the ethics of these two thinkers who shared aversion to hegelianism. The methodology used in the development of this work was the deductive with methodological technique the bibliographic

\footnotetext{
${ }^{1}$ Graduando em Filosofia pela Faculdade de Filosofia, Ciências e Letras de Cajazeiras - FAFIC. Email: luede_pb@hotmail.com.

2 Pós graduando lato sensu em Filosofia Contemporânea pela Faculdade de Filosofia, Ciências e Letras de Cajazeiras - FAFIC. Email: jheovannedv@,hotmail.com.
} 
analysis using the works of Schopenhauer: The World as Will and Representation, and Feuerbach: The Essence of Christianity, as well as some of his commentators. Ethics in Schopenhauer is compassion, that is, the feeling of putting yourself in the other's place. Even counting that Schopenhauer thought is atheistic, ethics of compassion is a christian conception that, for the philosopher of Dantzig, provides an ameliorating of the suffering caused by the shackle of the Will. In Feuerbach, there is no written strictly on ethics, which makes many reflections and conclusions subjective and necessary of a broad interpretation of the philosopher. The Feuerbach ethics is closely linked with his materialistic worldview. Man is a being endowed with affection, feelings, and all that is to be material, denying any possibility of a spiritual or metaphysical field. Thus, the ethics of sensitibity is the recognition that man is an individual and concrete being, where the guide of its action must be love, enabling a material experience of all KEYWORDS: Compassion, Sensibility, Will, Love, Contemporaneity.

\section{INTRODUÇÃO}

No século XIX o desenvolvimento de teorias filosóficas chegou a proporções inimagináveis, sendo considerado como os anos mais selvagens da filosofia (Cf. SAFRANSKI, 2011). Neste período, não se podia ser considerado contrário a esta afirmativa, pois foi a época de grandes pensadores como Feuerbach, Hegel, Kierkegaard, Marx, Nietzsche, Schopenhauer, entre outros.

O idealismo alemão (Fichte, Schelling e Hegel) foi a corrente mais estudada neste período, mas também a mais criticada, assim sendo, tanto para a admiração como para a rejeição, não se pode negar a sua grande influência no posterior advento de novas filosofias. Das críticas ao Idealismo surgiu a então conhecida esquerda hegeliana, filósofos que desenvolveram pensamentos profundamente contrários a Fichte, Schelling e Hegel. Dentre os muitos críticos será estudado neste trabalho dois deles: Schopenhauer e Feuerbach, precisamente suas concepções sobre a ética. Como Schopenhauer e Feuerbach concebiam a ética? Quais os seus fundamentos teóricos? E afinal, existem convergências ou divergências na concepção de ética nestes dois filósofos?

A ética de Schopenhauer é a da compaixão, identificado por ele como o ágape, principal virtude cristã, em que o indivíduo se coloca no lugar do outro. Por mais que o pensamento schopenhaueriano seja ateísta, a ética da compaixão trata-se de uma concepção cristã que para o 
filósofo de Dantzig, proporciona uma amenização ao sofrimento causado pelo grilhão da Vontade.

Esta negação da Vontade, ímpeto e essência do mundo, faz com que o indivíduo acabe com o egoísmo inerente a ele e perceba no outro ele mesmo, pois afinal, eles são constituídos pela mesma coisa, Vontade e representação. Ao mesmo tempo, esta ética é estendida aos animais que assim como o homem, também sofrem, devendo estes prezar pelo cuidado daqueles.

Já o pensamento ético de Feuerbach é, antes de tudo, uma crítica aos sistemas de Kant e de Hegel, assim este pensador elabora uma ética voltada ao homem, partindo do pressuposto que ela, assim como qualquer estudo, deve ser pautada pelo sensível. Neste sentido, o homem a partir de seus sentimentos e afecções, desenvolve um pensamento ético centrada no sensível, baseado no amor ao outro.

No que concerne ao desenvolvimento da ética do sensível, Feuerbach enaltece a importância do amor, da compaixão e do conceito de lei, enquanto ambos como constituintes da essência de deus, ou seja, do homem. Assim, a ética Feuerbachiana está intimamente ligada à visão materialista de mundo, onde o homem é um ser dotado de afeto, sentimentos, e tudo que o constitui como ser material, negando qualquer possibilidade de um campo espiritual ou metafísico. Portanto, ética da sensibilidade é o reconhecimento de que o homem é um ser individual e concreto, onde o marco de seu agir deve ser o amor, possibilitando uma vivência material entre todos.

O objetivo deste trabalho é o de descrever as principais ideias na ética de Schopenhauer e Feuerbach e estabelecer uma possível relação entre as duas concepções, aparentemente consonantes por se basearem em fundamentação ateísta.

Para tanto a metodologia utilizada no desenvolvimento deste trabalho foi a dedutiva com técnica metodológica a análise bibliográfica utilizando as obras de Schopenhauer: $O$ mundo como vontade e como representação, e a de Feuerbach: A essência do cristianismo e Princípios da filosofia do futuro, bem como alguns de seus comentadores.

Este trabalho está dividido em três capítulos, o primeiro: Vontade: a resposta para o enigma do mundo, onde é desenvolvida a metafísica da Vontade de Schopenhauer e sua estreita relação ao kantismo. Capítulo importante, pois o próprio Schopenhauer considera indispensável o conhecimento central de sua metafísica, isto é, a realidade como Vontade e como representação, para só então haver a compreensão dos diversos temas por ele tratados, dentre eles a ética. O segundo capítulo, A ética da compaixão, onde de fato será tratado o tema central em Schopenhauer e sua estreita relação conceitual com o amor cristão. E por fim, A ética da sensibilidade: uma nova filosofia, desenvolvimento das ideias de Feuerbach que é profundamente materialista, pois 
considera o ato ético como necessário para um bom convívio humano, deixando para a conclusão, além das considerações finais de todo o trabalho, as divergências ou convergências destes dois pensadores.

\section{Vontade: A resposta para o enigma do mundo}

Durante toda a história da filosofia a essência do mundo sempre esteve no rol das discussões metafísicas. Os filósofos tinham a necessidade de saber o que fazia tal objeto ser ele mesmo e não outro, e qual o lugar do sujeito na atitude de conhecer este objeto. Kant foi um destes pensadores que se debruçou no final da Modernidade no estudo da teoria do conhecimento ficando famoso por resolver a disputa entre o inatismo e o empirismo ${ }^{1}$.

Para Kant, não era o objeto que estava no centro do ato de conhecer e sim o sujeito e a partir dele que se conhecia o objeto, esta renovação foi nomeada por ele de Revolução Copernicana, em referência a atitude de Copérnico em dizer que não era a Terra e sim o Sol que estava no centro. Mas por mais que o sujeito fosse o centro do conhecimento, ele não conseguia conhecer por completo o objeto, pois o em-si permanecia inacessível. O fenômeno, ou seja, a realidade empírica era a única realidade que o sujeito podia conhecer, já a coisa-em-si, a essência destes fenômenos era uma incógnita que não se podia ter resolução.

Schopenhauer influenciado por Kant aproveita estes dois conceitos de fenômeno e coisa-emsi e vai utilizá-los em sua "organização filosófica", porém com algumas reformulações. Schopenhauer vai chamar o fenômeno de representação e a coisa-em-si que antes para Kant é incognoscível se torna na filosofia schopenhaueriana passível de conhecimento, sendo ela a

\footnotetext{
$1 \mathrm{O}$ inatismo era a corrente filosófica que afirmava que o conhecimento era anterior à experiência e, portanto, fruto das Ideias Inatas. Esta tese foi defendida pelos racionalistas Descartes e Leibniz se fortalecendo principalmente no continente Europeu. Já o empirismo, negava a noção de Ideias Inatas sendo admitindo por alguns que o ser humano nascia como uma tábula rasa e só depois da experiência era que o indivíduo construía o conhecimento. Foi defendido por Locke, Berkeley, Hobbes e Hume se consolidado principalmente na Grã-Bretanha. Desta forma, Kant percebe estas duas correntes em parte estão certas, pois existem os juízos analíticos a priori e os juízos sintéticos a posteriori. No juízo analítico a priori o predicado pode ser formado sem uma empiria desenvolvida por pura análise e o juízo sintético a posteriori está dependente à empiria desenvolvido por meio de uma síntese feita pelo sujeito. A "descoberta" de Kant foi admitir a existência dos juízos sintéticos a priori, ou seja, a síntese dos dois juízos anteriores e que o predicado não está no sujeito, mas é formado pela experiência, constituindo-se principalmente pelos cálculos matemáticos. São estes essenciais para a produção do conhecimento por acrescentarem algo novo àquilo que já conhecemos, pois "nos juízos sintéticos a priori todavia, carecemos inteiramente desse auxílio[experiência] [...] Todo nosso conhecimento especulativo apriorístico tem por objetivo e se apoia nestas proposições sintéticas, isto é, extensivas, porque as analíticas são sem dúvida muito importantes e necessárias mas só para alcançarmos a limpidez de conceitos que é requisito de uma síntese segura e ampla, servindo com um acréscimo realmente novo àquilo que já possuímos (e é sempre o mesmo)"(KANT, [s/d], p. 63, grifo do autor).

2 Schopenhauer era avesso à utilização do termo sistema que tanto foi utilizado por Hegel, seu inimigo teórico, fazendo com que ele considerasse sua metafísica como um "organismo" por se assemelhar a interelação inseparável dos órgãos de um corpo.
} 
Vontade. Assim, a diferença, segundo Schopenhauer, de sua filosofia com as anteriores não era o sujeito ou o objeto como causa e sim a representação. Diz Cacciola:

Schopenhauer afirma que sua filosofia, à diferença das demais, não se apresenta como um dogmatismo, já que não põe nem sujeito, nem o objeto como causa, mas parte "da representação como fato primeiro da consciência". Ora, o mundo como (als) representação, dada tanto a sua forma mais geral, distinção entre sujeito e objeto, como termos correlatos, quanto as formas do principio de razão que lhe são subordinadas, apresenta um caráter inteiramente relativo. É daí que surge a necessidade de buscar a essência íntima do mundo "num outro lado totalmente distinto da representação, num fato dado tão imediatamente a todo ser vivo". Esse fato é a Vontade (CACCIOLA, 1997, p. 33-34).

A Vontade é um ímpeto cego e irracional que domina toda a realidade fenomênica, sendo ela a causadora do sofrimento do mundo. Neste sentido, a Vontade por ser a essência de tudo, o sofrimento é inerente ao mundo, o que torna impossível de o ser humano escapar de suas mazelas e dores. Leibniz acreditava que este era o melhor dos mundos possíveis, mas como é que este mundo pode ser o melhor dos mundos possíveis, se nele há doenças, guerras, dores, por fim, sofrimentos? Para Schopenhauer este é o pior dos mundos possíveis, pior inclusive sobre aquilo que o homem consegue cogitar, pois inclusive sobre os seus próprios pensamentos estão subordinados a Vontade.

É a Vontade que ludibria o homem a querer buscar a felicidade, que não existe, o que há é apenas uma amenização do sofrimento. Enquanto que o prazer tem limites a infelicidade é ilimitada, o que torna o sofrimento a finalidade da nossa vida.

Se a FINALIDADE MAIS imediata e próxima de nossa vida não é o sofrimento, então nossa existência é o maior contrassenso do mundo. Pois é absurdo supor que a dor infinita, que se origina da miséria essencial à vida e da qual o mundo está repleto, seja sem propósito e puramente contingente. Nossa receptividade para a dor é quase infinita, já para o prazer possui limites estreitos. Embora toda infelicidade individual apareça como uma exceção, a infelicidade em geral constitui a regra. (SCHOPENHAUER, P/P II \148, p. 147, grifo do autor) ${ }^{1}$.

A exceção da infelicidade individual que Schopenhauer fala se encontra em homens que amenizam a ação da Vontade em suas vidas. Não são todos que conseguem essa proeza, por isso que o nosso filósofo os chama de Gênios por serem mais felizes do que a maioria da população. Estes Gênios são aqueles que praticam o ascetismo, contemplam o estético e têm caridade para com os outros ou para com os animais. Esta última é o que caracteriza sua ética: a da compaixão.

\footnotetext{
1 P/P II: Parerga e paralipomena (Tomo II). [Tradução F. C. Ramos como Verdade e Método (apenas parte do escrito)].
} 


\title{
A ÉTICA DA COMPAIXÃO
}

Afirmar ou negar o querer-viver são duas atitudes seguidas pelo indivíduo, segundo Schopenhauer. Ao afirmar o querer-viver, o indivíduo fica com a esperança de uma felicidade futura ou uma real satisfação na vida o que ocasiona ainda mais seu aprisionamento ao mundo e a subserviência em relação à Vontade, e consequentemente ao sofrimento. O caso contrário, ou seja, a da negação faz com que o indivíduo reconheça essa escravidão ao querer fazendo com que ele não mais queira. Há, portanto uma "liberdade" provisória do indivíduo “[...] em que o conhecimento leva a Vontade a pôr termo ao seu querer" (CACCIOLA, 1997, p. 155).

Esta atitude de reconhecer a Vontade como causadora do sofrimento não é algo que se possa ser ensinado ou advertido ao outro. Isto se dá porque a Vontade é livre e não se submete as regras, dicas ou métodos que funcionaram com alguns, além do mais, ninguém garante que o Gênio consiga por longo tempo permanecer ou conseguir negar a Vontade. Desta forma, a ética schopenhaueriana é descritiva, ou seja, não aceita um princípio norteador como o era a ética prescritiva de Kant.

Esta negação da Vontade é caracterizada pela compaixão, ou seja, o se colocar no lugar do outro assumindo para si o sofrimento alheio. Tal atitude é como que não existissem mais duas representações e sim uma única, desfazendo as diferenças e o egoísmo que é inerente ao ser humano.

\begin{abstract}
Para que eu possa querer o bem-estar de outrem é preciso que eu o queira como se fora o meu próprio, "para que ele possa ser o fim último de minha vontade": "Isso pressupõe, necessariamente, que eu o sinta como se fora apenas meu". Esse motivo só será eficaz se for pressuposta uma identificação com o outro, ou seja, uma total supressão da diferença entre esse outro e a minha pessoa, diferença esta na qual se baseia o egoísmo, que é o motivo antimoral por excelência. Já que para Schopenhauer nós não podemos nos pôr na pele do outro, a identificação só é possível por meio do conhecimento, ou seja, da representação que tenho desse outro, da qual resultará uma ação em que a diferença é suprimida (CACCIOLA, 1997, p. 157, grifo da autora).
\end{abstract}

A compaixão é uma atitude já mencionada pelos cristãos que a exemplo de Jesus, o indivíduo, se possível, doa sua vida pelo outro. É um amor incondicional reconhecido no meio teológico cristão de ágape ou caritas a mais importante virtude segundo a primeira epístola de Paulo aos Coríntios ${ }^{1}$. Desta forma, podemos afirmar categoricamente que a ética cristã é a mesma da utilizada nos escritos de Schopenhauer, “[...] percebe-se que não há distinção entre a

\footnotetext{
${ }^{1}$ Para a teologia cristã existem três virtudes teologais, são elas: fé, esperança e amor. Mas, ao contrário do que muitos pensam, segundo Paulo, a fé não é a mais importante delas, e sim, o amor. É precisamente na primeira carta enviada a Corinto em que ele escreve em uma linguagem quase poética, a sua exaltação ao amor, pois esta virtude está acima do que falar a língua dos anjos e dos homens, do que o dom de profetizar, o ato de distribuição dos bens ou mesmo da fé e da esperança (Cf. BÍBLIA SAGRADA. 1Co 13:1-13).
} 
compaixão defendida por Schopenhauer e a encontrada no Cristianismo, pois ambas impelem para a mesma tomada de decisão: ajudar ao outro que esta sofrendo enquanto se puder ajudar" (PAMPLONA; SILVA, 2013, p.309). Mas vale ressaltar, que o filósofo de Dantzig não era teísta e muito menos cristão, porém sua organização filosófica reconhece na atitude de Jesus, São Francisco de Assis ou mesmo em orientais como Buda, como personalidades que desenvolveram seu ascetismo e a capacidade impressionante de amar.

Agape é um amor puro e desinteressado que não visa nada em troca, ao contrário do amor próprio que aprisiona o indivíduo à Vontade. Assim, o ágape identificado por Schopenhauer como o mesmo sentimento de compaixão tem a capacidade de aliviar o sofrimento seja ele pequeno como grande. Nas palavras de Schopenhauer “[...] o amor puro ( $\alpha \gamma \alpha \pi \eta$, caritas), em conformidade com sua natureza, é compaixão; e o sofrimento que ele alivia, ao qual pertence todo desejo insatisfeito, tanto pode ser grande quanto pequeno" (MVR I, $\int 67$, p. 477) ${ }^{1}$.

Por mais que a compaixão ser um sentimento sublime e de uma superioridade metafísica em relação aos outros sentimentos, ela não dura eternamente. O véu Maia que antes foi rascado pelo ágape retorna ao ser humano com a proposta ilusória de gozos e o bem estar, fazendo com que ele retorne a antiga realidade de submissão à Vontade (Cf. SCHOPENHAUER, MVR I, $\mathbb{S}$ 68, p. 482).

A compaixão é uma virtude que desfaz o egoísmo natural do ser humano, ele adquire a real percepção de que ele é Vontade assim como todo ser vivente que existe, desde o homem aos animais.

\footnotetext{
Se aquele Véu de Maia, o principium individuationi, é de tal maneira retirado aos olhos de um homem que este não faz mais diferença egoística entre a sua pessoa e a de outrem, no entanto compartilha em tal intencionalidade dos sofrimentos alheios como se fossem os seus próprios e assim é não apenas benevolente no mais elevado grau mas está até mesmo pronto a sacrificar o próprio indivíduo tão logo muitos outros precisem ser salvos; então, daí segue-se automaticamente que esse homem reconhece em todos seres o próprio íntimo, o seu verdadeiro si-mesmo, e desse modo tem de considerar também os sofrimentos infindos de todos os viventes como se fossem seus: assim, toma para si mesmo as dores de todo o mundo; nenhum sofrimento lhe é estranho (SCHOPENHAUER, MVR I, \68, p. 481).
}

O sofrimento não é estranho para o indivíduo quando ele rasga o véu Maia, pois ele se dá de conta do outro, que na verdade é ele mesmo. Vale resaltar, que Schopenhauer faz uma inovação na ética ao introduzir nela o cuidado aos animais, contrária em relação às anteriores que consideravam a ação ética apenas uma relação entre humanos. É necessário ter compaixão com

\footnotetext{
${ }^{1}$ MVR I: O mundo como Vontade e como representação (Tomo I).
} 
os animais, porque eles sofrem e tem o entendimento, como é o caso do cão que retribui o carinho ao ser humano, bem como uma ampla sabedoria e esperteza em suas atitudes ${ }^{1}$.

\section{A ÉTICA DA SENSIBILIDADE: UMA NOVA FILOSOFIA}

No decorrer do pensamento de Feuerbach, surge, com dificuldades, a conceituação de uma ética propriamente dita em seus escritos, mas, indiretamente em seus constructos, observamos o nascimento de uma ética pautada na sensibilidade e na ressignificação dos sentidos e das afecções humanas. Tal pensamento ético brota como uma crítica às éticas precedentes, especialmente a de caráter deontológica desenvolvida por Immanuel Kant.

Antes de adentramos propriamente nos fundamentos da ética do nosso pensador, é necessário conceituar o que constitui a essência humana. "Essa essência humana é definida como razão, coração e vontade" (ALBINATI, 2015, p. 79). Tal essência também constitui a da divindade, pois, esta é uma hipóstase da nossa natureza. Esta essência do homem torna-se como todo o constitutivo de sua natureza. "Estes três componentes traduzem-se em querer, sentir e pensar, compondo toda a essência humana e é neste processo que há uma troca entre o deus cristão trinitário em um deus do homem totalmente ligado à realidade.” (ABREU \& LIRA, 2015, p. 376). Tais fundamentos de nossa existência constituem o pilar básico das reflexões do nosso teórico, bem como, as reflexões acerca do seu estudo sobre o agir humano.

Quais os fundamentos de uma ética da ou para a sensibilidade no pensamento feuerbachiano? Tal pergunta é o ponto chave de nossa investigação. Feuerbach tece críticas a uma ética racionalista que tente ligar razão e sentimentos. "Feuerbach compreende a ética racionalista como a expressão de um déficit de realização da essência humana, a ser corrigido por uma nova filosofia que se torne uma nova religião.” (ALBINATI, 2015, p. 80). Essa ética racionalista e deontológica acabam por destruir a nossa essência, pois, prioriza o transcendente em detrimento do imanente. Kant comete um erro ao verificar que o agir humano estaria pautado em um dever e na racionalidade, pois, isso acaba por destruir a entrega do homem aos sentidos e as afecções ocasionando uma alta valorização da razão. O nosso teórico exemplifica da seguinte forma:

\footnotetext{
1 Schopenhauer foi um defensor dos direitos dos animais ao ponto de inseri-los em sua ética, reprovando aqueles que maltratam um cão ou os que prendiam uma ave em uma gaiola. Ele amava os cães, tanto que ele tinha um poodle que se chamava Atma, caracterizando tanto ele como seus admiradores que o imitavam na atitude de criarem também um poodle.
} 
Homens puramente racionais, homens que para nós simbolizam e personificam a essência da razão, ainda que num aspecto unilateral, mas exatamente por isso característico, são isentos de angústia, paixões e excessos dos homens sentimentais; não se prendem a nenhum objeto finito, i. é, determinado, de maneira passional; não se empenham, são livres (FEUERBACH, 1997, p.78).

Com isso, foi observado que nenhuma ética pode ser pautada exclusivamente na razão, pelo fato de com isso haver um desprezo aos sentimentos. Feuerbach reconhece neste trecho, a ética kantiana enquanto supressora da liberdade humana, ela suprime e dá valor a apenas um dos atributos da essência humana, o da razão abstrata. O fundamento da ética Kantiana torna a moral humana nula e impenetrável ao que são mais importantes para nós, os sentidos.

É necessária para dar base a uma nova ética, uma nova filosofia. "Uma nova filosofia, à qual o autor se propunha, teria que refundar a relação imediata, sensível, intuitiva, entre ser e pensar, reconhecendo a primazia do ser e a legitimidade dos sentidos" (ALBINATI, 2015, p. 81). É notório no pensamento de Feuerbach, que tal refundação da filosofia é iniciado em uma crítica à filosofia idealista de Hegel, bem como o seu desprezo pela realidade sensível. Uma nova filosofia deve ser centrada nos sentidos, no material, no homem. Tal filosofia se transformaria em uma religião, onde haveria uma reconciliação entre razão e afetividade, inaugurando uma religião do e para o homem.

O que também constitui essencialmente a ética da sensibilidade é a primazia do amor perante todos os outros atributos da nossa essência.

O amor é o laço de união, o princípio de mediação entre o perfeito e o imperfeito, entre o ser sem pecado e o pecador, entre o geral e o individual, a lei e o coração, o divino e o humano. O amor é o próprio Deus e sem ele não há Deus. O amor transforma o homem em Deus e Deus no homem. O amor fortifica o fraco e enfraquece o forte, humilha o soberbo e enaltece o humilde, idealiza a matéria e materializa o espírito. $\mathrm{O}$ amor é a verdadeira unidade Deus e homem, espírito e natureza. Amar significa, partindo do espírito, anular o espírito; partindo da matéria, anular a matéria. Amor é materialismo; o amor imaterial é nonsense (FEUERBACH, 2013, p. 75).

É evidente o quão é forte a ligação do amor agindo sobre a ética, especialmente na criação de uma ética pautada em nós. "O amor precisa ser material para atender às necessidades humanas, estas atacadas pela forma simplória de ver o homem e o amor humano pela religião cristã." (ABREU; LIRA, 2015, p. 380).

Outro constructo necessário para entendermos o pensamento moral de Feuerbach nasce na dificuldade do homem criar um preceito moral possível de ser realizado. É necessário criarmos algo além, em que "tal consciência estaria presente na representação religiosa, através da consideração da divindade não só como lei da razão, mas também como um ser que ama”. 
(ALBINATI, 2015, p. 82). Mas isto não pode ser pautado em um Deus, e sim no próprio homem, enquanto um ser dotado de compaixão. Nisto podemos observar, a aproximação entre as duas éticas propostas neste artigo. O filósofo de Landshut também considera a compaixão como um dos marcos essencial para a construção do agir moral. "A lei condena, mas o coração se compadece do pecador. A lei só me afirma como um ser abstrato, mas o coração como um ser real.” (FEUERBACH, 1997, p. 90). É evidente que há, de certa forma, uma apropriação de termos cristãos para a construção de uma ética não cristã.

Em que termos esse agir baseado na compaixão se desenvolve ou se aplica? Segundo o nosso teórico: "É ele posto não como ser amoral, mas como um ser não moral, como um ser mais do que moral, em síntese, um ser humano" (FEUERBACH, 2007, p. 76). É límpido o esforço utilizado para transformar e justapor toda a história do pensamento, imprimindo uma troca imediata entre deus e o homem, mas não seria um antropocentrismo, seria como uma antropologia centrada em nós. Nosso agir moral precisa ser centrado não em um ser amoral, mas em um ser moral, em outras palavras, exclusivamente, um ser sensível, que não baseie seus preceitos morais em algo universal e unicamente racional. Explicita o filósofo de Landshut:

Não são os seres abstratos, (não!) somente os seres sensíveis são misericordiosos. A misericórdia é o senso de justiça dos sentidos. Por isso Deus não perdoa os pecados humanos em si mesmo, como um Deus abstrato da razão, mas em si como homem, como um ser sensorial, que se torna carne (FEUERBACH, 2007, p. 76).

Pode-se verificar, mais uma vez, a crítica à teologia, especialmente a de cunho cristã no que concerne a sua ética espiritualista e idealista. Porém, é usado o exemplo da trindade para exemplificar a relação saudável entre nós. A relação entre a pessoa do Deus Pai, e o Deus Filho, representa a reciprocidade, a relação entre Eu-Tu. Enquanto a terceira pessoa da trindade, o Deus Espirito Santo, representa a união entre as três pessoas da trindade, ou seja, o conceito de comunidade, de união, de alteridade, do se importar com o outro. Esse direcionamento proposto por Feuerbach em relação às pessoas da trindade com a Ética, cria segundo Marx as próprias bases do socialismo, onde essa ideia de união seria um espectro do comunismo desenvolvido posteriormente nos estudos de Marx e Engels.

Eu não atribuo qualquer valor especial a este julgamento, mas tenho o prazer de aproveitar esta oportunidade para expressar tamanha estima e - se permiteme o uso da palavra - o Amor que sinto por você. Suas obras: Princípios da filosofia do Futuro e a Essência da Religião, são as obras de maior peso de toda literatura alemã junta. Em suas obras, é dado: não sei se propositalmente - uma 
fundamentação filosófica ao socialismo, e, nós, comunistas interpretamos isso desde o primeiro momento. (MARX, 1844).

Seguindo nas fundamentações da Ética da sensibilidade feuerbachiana, é de real importância um texto do autor para compreendermos melhor a sua visão sobre a humanidade e o agir dela. Tal texto é o Princípios da filosofia do futuro, escrito em 1843.

É necessário pensar uma nova filosofia que assentaria tudo, para depois pensarmos os pormenores, que seria o caso da Ética, da Antropologia, da Teologia, que não passa de uma transformação da antropologia, como a base de todo o pensamento humano.

Uma nova filosofia, à qual o autor se propunha, teria que refundar a relação imediata, sensível, intuitiva, entre ser e pensar, reconhecendo a primazia do ser e a legitimidade dos sentidos, de forma a apresentar-se como uma nova religião na medida em que assimilasse a essência da religião (a reconciliação entre afetividade e razão) em sua naturalidade, uma vez desfeitas as ilusões da teologia. (ALBINATI, 2015, p. 81).

Esta nova filosofia, que seria uma nova forma de rever a religião, visto que atualmente, ela se configura como algo nocivo ao ser humano, proclama a primazia do sensível e a absolutização do amor como agente máximo da perfeição moral e como algo que está acima de tudo, até do próprio Deus. No que se assenta propriamente essa nova filosofia? Do que ela é constituída? Como ela pode trocar a religião?

Nada mais do que o entendimento e a essência do homem separado das determinações que, sejam elas reais ou imaginárias, constituem, num momento dado, os limites do homem. Quem não tem o entendimento cortado dos sentidos e não considera os sentidos como limitações também não representa para sí como o entendimento mais elevado e verdadeiro o entendimento privado dos sentidos (FEUERBACH, 1988, p. 15).

A nova filosofia deve ser centrada, conforme já explicitado, na sensibilidade, só assim ela será capaz de vencer as nocividades das filosofias espirituais e idealistas, bem como, os constructos religiosos cristãos. É necessário elevar o coração, o amor ao entendimento para fabricarmos uma ligação entre o pensar e o real, entre razão e sensibilidade.

Assim, a Ética da sensibilidade, pode ser constituída da seguinte forma:

\footnotetext{
${ }^{1}$ Trecho retirado da carta de Marx a Feuerbach, escrita em 11 de Agosto de 1844 e enviado no mesmo ano para seu destinatário. No original em espanhol: "No atribuyo ningún valor especial a este ensayo, pero me es grato aprovechar la ocasión para expresarle la alta estimación y - si me permite la palavra - el amor que siento por usted. Su Filosofia del futuro y su Essencia la fe son, desde luego, a pesar de su volumen reducido, obras de mayor peso que toda la literatura alemana actual junta. En estas obras há dado usted - no se si deliberadamente - una fundamentación filosófica al socialismo, y los comunistas han interpretado asi estos trabajos desde el primer momento".
} 
Não significa, assim, um pieguismo da misericórdia ou uma arbitrariedade da vontade, como pensava Kant ao dizer da volubilidade da vontade diante das inclinações, mas um reconhecimento da sensibilidade que afirma o humano a partir da individualidade concreta, objetiva, correlacionada à objetividade. Os sentidos são as portas de apreensão da objetividade. O amor é a afecção que traduz a dependência humana da objetividade, seja na forma dos seres naturais, seja na forma dos outros seres humanos (ALBINATI, 2015, p. 84).

Diante de tal constructo, podemos notar a importância de Feuerbach no que toca a uma nova Ética, uma nova forma de ver o mundo. Seus estudos são de real importância ao desenvolvimento de uma sociedade mais livre e centrada no amor ao próximo.

\section{Considerações finais}

Arthur Schopenhauer e Ludwig Feuerbach foram filósofos que questionaram a Hegel, desenvolvendo a chamada esquerda hegeliana. O primeiro ficou conhecido pelo o seu pessimismo filosófico, já o segundo pelo seu ateísmo e a consideração da teologia como sendo uma antropologia.

A ética da compaixão em Schopenhauer é a atitude de se colocar no lugar do outro, desfazendo-se do egoísmo inerente ao ser humano, constituindo assim, de uma virtude que não visa nada em troca. Neste sentido, este sentimento altruísta nega a Vontade favorecendo uma amenização de seus sofrimentos. Porém, o grilhão da Vontade é superior negando a liberdade na realidade fenomênica.

Já em Feuerbach, não há um escrito estritamente ligado a ética, o que torna muitas das reflexões e conclusões subjetivas e necessárias de uma ampla interpretação do filósofo. A ética do filósofo de Landshut, sendo materialista, não considera um ser divino, mas apenas o ser humano que deve sempre tratar outro por igual.

No que concerne a aproximação da concepção ética entre estes dois pensadores, foi observado que ambos adotam a compaixão como fundamento. A compaixão em Schopenhauer é adotada como fundamento máximo de sua ética, constituindo uma aproximação ao amor cristão. Já no pensamento de Feuerbach, a compaixão é tomada como um atributo de menor importância em comparação ao pensamento do filósofo de Dantzig. Segundo o filósofo de Landshut, o amor, a compaixão, a alteridade e a lei são os atributos da sua fundamentação ética. $\mathrm{O}$ amor e a lei no decorrer das suas obras, são de suma importância do que o seu conceito de compaixão. O amor e 
a lei são representados por Deus Pai, enquanto que a compaixão é representada pelo Deus Filho, e a alteridade como Deus Espirito Santo.

Outra relação entre os dois filósofos da esquerda hegeliana é o ateísmo como princípios de suas éticas. Para Schopenhauer Deus não existe e não existe uma ordem organizadora do muito e sim um ímpeto irracional que é a Vontade. Para Feuerbach, Deus é uma hipóstase do homem, onde o indivíduo coloca seus desejos, vontades e perfeições em um ser metafísico. Nisto decorre, a transformação da teologia em antropologia. Desta forma, a ética schopenhaueriana e feuerbachiana é descritiva, ou seja, não aceita um princípio norteador como o era a ética prescritiva de Kant.

Desta forma, a compreensão do pensamento ético tanto em Schopenhauer como em Feuerbach são essenciais para a compreensão da contemporaneidade, haja vista, que os seus questionamentos são arcabouço para as principais correntes e ideias que norteiam o pensamento atual.

\section{REFERÊNCIAS}

ABREU, Jheovanne Gamaliel Silva de. A autonomia da Vontade e a não liberdade no amor, segundo Arthur Schopenhauer. 2015. 47 f. (Monografia) - Faculdade de Filosofia, Ciências e Letras de Cajazeiras. Cajazeiras, 2015.

; LIRA, Luédlley Raynner de Souza. O amor nas filosofias de Arthur Schopenhauer e Ludwig Feuerbach. Anais do IV Congresso Internacional Ludwig Feuerbach: antropologia e ética. Fortaleza, v. 1, 2016, p.371-382.

ALBINATI, Ana Selva. Feuerbach: fundamentos para uma ética da sensibilidade. Anais do IV Congresso Internacional Ludwig Feuerbach: antropologia e ética. Fortaleza, v. 1, 2016, p.371-382.

BARBOZA, Jair. Schopenhauer: a decifração do enigma do mundo. São Paulo: Moderna, 1997.

BÍBLIA SAGRADA. Tradução João Ferreira de Almeida. Almeida Revista e Atualizada. 2.ed. Barueri: SBB, 2008.

CACCIOLA, Maria Lúcia Mello e Oliveira. Schopenhauer e a questão do dogmatismo. São Paulo: Edusp/Fapesp, 1994. 
FEUERBACH, Ludwig. A essência do cristianismo. Tradução: José da Silva Brandão. Campinas: Papirus, 1997.

A Essência do Cristianismo. Tradução de José da Silva Brandão. 4. ed. Petropólis: Vozes, 2013, p. 343.

Princípios da filosofia do futuro. Tradução: Artur Morão. Lisboa: edições 70, 1988.

KANT, Immanuel. Crítica da Razão Pura. Tradução Wilson Veloso. In. O pensamento vivo de Kant. São Paulo: Martins, [s.d.].

MARX, Karl. [Carta]. 11 ago. 1844, Paris para FEUERBACH, Ludwig. Disponível em: < https://artilleriainmanente.noblogs.org/post/2016/05/07/carta-de-karl-marx-a-ludwigfeuerbach/> Acesso em: 19 mai 2016.

PAMPLONA, Simião Severino; SILVA, Antunes Ferreira da. Arthur Schopenhauer e a relação entre o princípio ético da compaixão e o cristianismo. In. PAVÃO, Aguinaldo (org.). Anais [do] V Congresso Nacional de Filosofia Contemporânea. Londrina: UEL, 2013, p. 303-311.

SCHOPENHAUER, Arthur. O mundo como vontade e como representação. Tradução Jair Barboza. São Paulo: UNESP, 2005.

Sobre a filosofia e seu método. Tradução Flamarion Caldeira Ramos. São Paulo: Hedra, 2010. 